\title{
MicroRNA and messenger RNA profiling reveals new biomarkers and mechanisms for RDX induced neurotoxicity
}

\author{
Youping Deng ${ }^{1,2^{*}}$, Junmei $\mathrm{Ai}^{2}$, Xin Guan ${ }^{3}$, Zhaohui Wang ${ }^{1,8}$, Bin Yan ${ }^{4}$, Daqin Zhang ${ }^{5}$, Chang Liu', \\ Mitch S Wilbanks ${ }^{6}$, Barbara Lynn Escalon ${ }^{6}$, Sharon A Meyers ${ }^{7}$, Mary Qu Yang ${ }^{9,10}$, Edward J Perkins ${ }^{6}$
}

From 2014 International Conference on Advances in Big Data Analytics

Las Vegas, NV, USA. 21-24 July 2014

\begin{abstract}
Background: RDX is a well-known pollutant to induce neurotoxicity. MicroRNAs (miRNA) and messenger RNA (mRNA) profiles are useful tools for toxicogenomics studies. It is worthy to integrate MiRNA and mRNA expression data to understand RDX-induced neurotoxicity.

Results: Rats were treated with or without RDX for $48 \mathrm{~h}$. Both miRNA and mRNA profiles were conducted using brain tissues. Nine miRNAs were significantly regulated by RDX. Of these, 6 and 3 miRNAs were up- and downregulated respectively. The putative target genes of RDX-regulated miRNAs were highly nervous system function genes and pathways enriched. Fifteen differentially genes altered by RDX from mRNA profiles were the putative targets of regulated miRNAs. The induction of miR-71, miR-27ab, miR-98, and miR-135a expression by RDX, could reduce the expression of the genes POLE4, C5ORF13, SULF1 and ROCK2, and eventually induce neurotoxicity. Overexpression of miR-27ab, or reduction of the expression of unknown miRNAs by RDX, could up-regulate HMGCR expression and contribute to neurotoxicity. RDX regulated immune and inflammation response miRNAs and genes could contribute to RDX- induced neurotoxicity and other toxicities as well as animal defending reaction response to RDX exposure.
\end{abstract}

Conclusions: Our results demonstrate that integrating miRNA and mRNA profiles is valuable to indentify novel biomarkers and molecular mechanisms for RDX-induced neurological disorder and neurotoxicity.

\section{Introduction}

Hexahydro-1,3,5-trinitro-1,3,5-triazine (RDX), is a well known contaminant to territory, soil and ground water due to military and manufacturing activities. A series of studies have demonstrated that RDX can cause neurotoxicity including seizure in human and animals [1-4]. RDX can also induce immunotoxicity in rats [5-7].

While many effects of RDX exposure are known, the molecular mechanisms of RDX caused toxicity have not been well characterized. It appears that RDX binding to the $\mathrm{GABA}_{\mathrm{A}}$ receptor convulsant site maybe the primary mechanism of seizure induction by RDX and that

\footnotetext{
* Correspondence: youping_deng@rush.edu

'Wuhan University of Science and Technology, Wuhan, Hubei 430081, China Full list of author information is available at the end of the article
}

reduction of GABAergic inhibitory transmission in the amygdala is involved in the generation of RDX-induced seizures[8-10]. But more mechanisms still needed to be studied such as epigenetic mechanisms.

Recently, It was [11] found RDX exposure could significantly alter a large number of miRNA expression in mouse brain and liver tissues with a 28 day long term exposure. MiRNAs are endogenous, small non-coding RNAs, usually 18-25 nucleotides long, have been found to play crucial roles in post-transcriptionally regulation of mRNA. MiRNAs have been found to involve in almost all fundamental important biological processes and diseases including neurological diseases and nervous system function [12]. MiRNAs carries out its function by specifically binding 3'UTR of mRNA to interrupt 
mRNA translation or cause degradation of transcripts [13-15]. Recent reports suggest that miRNA could play an opposite role by activating a gene expression at certain conditions $[16,17]$.

We use rat as a model species to investigate the impact of RDX on both miRNA and mRNA expression in rat brain tissues with a sub-acute short term exposure $(48 \mathrm{~h})$. The objectives of the study are to see whether we could see an across species conserved miRNA expression between rat and mouse, find overlapped targets between the putative targets of regulated miRNAs and mRNA genes regulated by RDX, identify early expression altered miRNAs and genes as new markers for assessing RDX induced neurotoxicity, and further understand the molecular mechanisms of RDX caused neurotoxicity. Since that miRNAs are highly conserved between humans and rats, this study should improve our understanding of the molecular mechanisms of RDX induced neurological disorders and diseases.

There are still very few studies to use miRNA expression profiles for characterizing RDX caused toxicity. There is no report to integrate RDX altered miRNA and mRNA expression profiles.

\section{Materials and methods Chemical}

RDX (purity > 99\%) was obtained from Stan Caulder (Naval Surface Warfare Center, Indianhead, MD, USA).

\section{Animals and Treatment}

Female Sprague-Dawley rats (175-225 grams) were from the in-house breeding colony (College of Pharmacy, University of Louisiana at Monroe [ULM] and treated in accordance with the Guide for Use and Care of Animals [18]. Breeders were from Harlan-Sprague Dawley in Madison, WI. Housing consisted of a $12 \mathrm{~h}$ light/dark cycle with ad libitum access to tap water and rodent chow (Harlan/Teklad 7012, Madison, WI). Rats were housed individually in polycarbonate cages on hardwood bedding (Sani-chips, Harlan/Tekland, Madison, WI) one week prior to treatment. Food was withdrawn the night before treatments, which were administered by gavage between 8 and 10 AM. Study protocols were preapproved by the Institutional Animal Care and Use Committee of the University of Louisiana at Monroe (Animal Welfare Assurance Number A3641-01).

Groups of rats were weighed and randomly assigned to treatment. Treatments were vehicle $(5 \% \mathrm{v} / \mathrm{v}$ DMSO in corn oil), RDX (47 mg/kg). Rats were observed continuously for the first hour after dosing, hourly for $8 \mathrm{~h}$ and daily thereafter. Moribund rats were euthanized with $\mathrm{CO}_{2}$. At 48 hours after treatment, survivors were anesthetized with $\mathrm{CO}_{2}$. A portion of the brain was removed and flash frozen in liquid $\mathrm{N}_{2}$ and stored at $-70^{\circ}$ $\mathrm{C}$ for miRNA and mRNA microarray analyses.

\section{Total RNA extraction}

Total RNA was extracted from about $30 \mathrm{mg}$ of brain tissue. Tissues were homogenized in the lysis buffer with FAST Prep-24 from MP before using RNeasy kits (Qiagen). Total RNA concentrations were measured using NanoDrop ${ }^{\circledR}$ ND-1000 Spectrophotometer (NanoDrop technologies, Wilmington, DE, USA). The integrity and quality of total RNA was checked on an Agilent 2100 Bioanalyzer (Palo Alto, CA). The gel-like images generated by the Bioanalyzer show that total RNAs have two bands, represent $18 \mathrm{~S}$ and 26S RNA of mammalian RNA. Nuclease-free water (Ambion) was used to elute total RNA.

\section{MicroRNA extraction}

We extracted total miRNA from each sample using the mirVana miRNA Isolation Kit (Ambion, Austin, TX) according to the manufacturer's instructions. Briefly, 0.03-0.05 g tissues were weighed and placed in a new 2 - $\mathrm{mL}$ micro-centrifuge tube, followed by adding $300 \mu \mathrm{L}$ lysis/binding buffer. Then, the tissues were thoroughly disrupted and homogenized using a Sonic Dismembrator (model 100, Fisher Scientific, Atlanta, GA). After homogenization, we added $30 \mu \mathrm{L}$ miRNA homogenate additive to each tissue lysate, vortexed it for $10 \mathrm{sec}$, and then incubated it on ice for $10 \mathrm{~min}$. After washing, we eluted the total RNAs using $100 \mu \mathrm{L}$ elution buffer provided in the miRNA isolation kit. We performed all these operations on ice. The extracted RNA was quantified using a NanoDrop ND-100 spectrophotometer (NanoDrop Technologies, Wilmington, DE), aliquoted, and immediately stored at $-80^{\circ} \mathrm{C}$ until analysis.

\section{MicroRNA microarray hybridization}

The miRNA micro-array analysis was performed by LC Sciences (Houston, TX) as described previously [11]. Briefly, the assay started with approximately $6 \mu \mathrm{g}$ total RNA. After the total RNAs were fractionated by size using a YM-100 Microcon centrifugal filter (Millipore, Billerica, MA), poly(A) tails were added to RNA sequences with lengths less than 300 nucleotides using poly(A) polymerase. Then, an oligonucleotide tag was ligated to the poly(A) tail for later fluorescent dye staining. RNA samples from brain extracts were hybridized overnight using two different tags on a $\mu$ Paraflo microfluidic chip using a microcirculation pump developed by Atactic Technologies (Houston, TX).

\section{mRNA microarray hybridization}

mRNA microarray hybridization was done as described previously[19]. Briefly cDNA from 1 ug total RNA was synthesized, hybridized to arrays, and detected by secondary 
hybridization to Alexa647 and Cy3 dendrimer oligonucleotides using an Array900 detection kit per manufacturer's instructions (Genisphere, Hatfield, PA). cDNA was hybridized to $8 \mathrm{~K}$ Sigma/Compugen rat 70-mer oligonucleotide libraries arrayed on glass slides (Center for Applied Genomics, Newark, NJ http://www.cag.icph.org/).

\section{MiRNA microarray data analysis}

MiRNA microarray was normalized by Lowess normalization algorithm using GeneSpring 10.0 (Agilent Technologies, Foster City, CA, USA). We first filtered substance according to flags. All substances that were at least $50 \%$ of samples in any of 2 out of 2 conditions (control group and RDX treatment group) have present calls according to the feature extraction software data will be remained. 215 substances were left after the flag filtering. We also judged a miRNA detectable using at least three criteria: $a$ ) signal intensity bigger than three times background standard deviation; $b$ ) spot coefficient of variance $(\mathrm{CV})<0.5$, in which we calculated $\mathrm{CV}$ as (standard deviation)/(signal intensity); and $c$ ) at least two spots of four technical repeats in each chip and two of three biological replicates in either control or treatment group have signal greater than three times background standard deviation. We found that 178 miRNAs could be detected in either control or treatment group, and were also in the 215 miRNA list. Therefore, 178 detected miRNAs were employed to identify differentiated miRNAs in rat brain after exposure to RDX. Differentiated miRNAs were computed using un-paired T-test with a cut off $\mathrm{p}$ value $<=0.05$ and fold change $>=1.2$ (corrected by Benjamini Hochberg at a FDR $<=0.05)$.

\section{MRNA microarray data analysis}

MRNA microarray data analysis was done as we described previously [20,21]. Briefly, the data was normalized based on Lowess normalization method, Bayesian statistical analysis with 5\% FDR was used to identify differential genes between two groups.

\section{MiRNA target prediction}

Three algorithms were used to predict target genes of miRNAs. These three algorithms are miRBase [22], TargetScan [23] and PicTar [24].

\section{Reverse-transcription quantitative PCR (QRT-PCR)}

We selected miRNAs with aberrant expression in microarray analysis and then validated them using qRT-PCR on an ABI7300 system (Applied Biosystems, Foster City, CA). We used TaqMan miRNA assays to detect and quantify mouse miRNAs using stem-loop RT-PCR according to the manufacturer's instructions.

\section{Gene functional analysis and network construction}

Physiological process and pathway analyses were performed using the Ingenuity pathway analysis (IPA) tool. A physiological process or a pathway with an enrichment $\mathrm{p}$ value $<=0.05$ was considered to be significant (Ingenuity Systems, Inc., Redwood City, CA). Gene networks were constructed based on the IPA tool. A score was assigned to a network according to the fit of the original set of significant genes. This score reflects the negative logarithm of the $\mathrm{p}$ value that indicates the likelihood of the focus genes in a network being found together due to random chance [25].

\section{Results}

\section{Regulation of miRNA expression in the brain tissues of} rats exposed to RDX

To determine whether the expression profile of miRNAs changes in response or RDX, we analyzed global expression of mature miRNAs in the brain tissues of rats treated with RDX. Rats were treated with RDX at a dose $(47 \mathrm{mg} / \mathrm{kg}$ ) for $48 \mathrm{~h}$. Three control and treatment animals were used. Brain tissues from treated and control rats were used for miRNA profiling. There were 344 rat miRNAs and 50 control molecules, and each miRNA was represented by 4 technical replicated spots on each chip. The Lowess normalization was employed to remove the systematic error of the experiments. Regardless control (Figure 1A) or RDX (Figure 1B) treated samples, the original data showed a clear bias skewed distribution. After the normalization, the bias distribution was removed in both control (Figure 1A) and RDX (Figure 1B) treated samples. Nine miRNAs were differentially regulated by RDX with a cut off $\mathrm{p}$ values $(<=0.05)$ and fold change $(>=$ 1.2) (Table 1). Of these 9 miRNAs, 6 miRNAs including miR-98, miR-27b, miR135a, miR-7a, miR-674-5p and miR-27a were significantly up-regulated by RDX. The expression of miR-320, miR-129* and miR-342-3p was significantly down-regulated by RDX.

Using these 9 miRNAs, we performed a two-way hierarchical clustering analysis. The samples were divided into two clusters: three control samples were in a one cluster and three RDX treated sample were in the other cluster. The 9 miRNAs were also grouped into two clusters: 6 upregulated miRNAs in a cluster and 3 down-regulated miRNAs in the other cluster (Figure 2).

\section{Computational predictions of the putative targets of regulated miRNAs}

In order to identify the putative targets or regulated miRNAs, we selected three most popular computational algorithms: miRBase, PicTar and TargetScan. We chose target genes based on a target gene that was recognized by at least two algorithms. In addition, we also counted target 


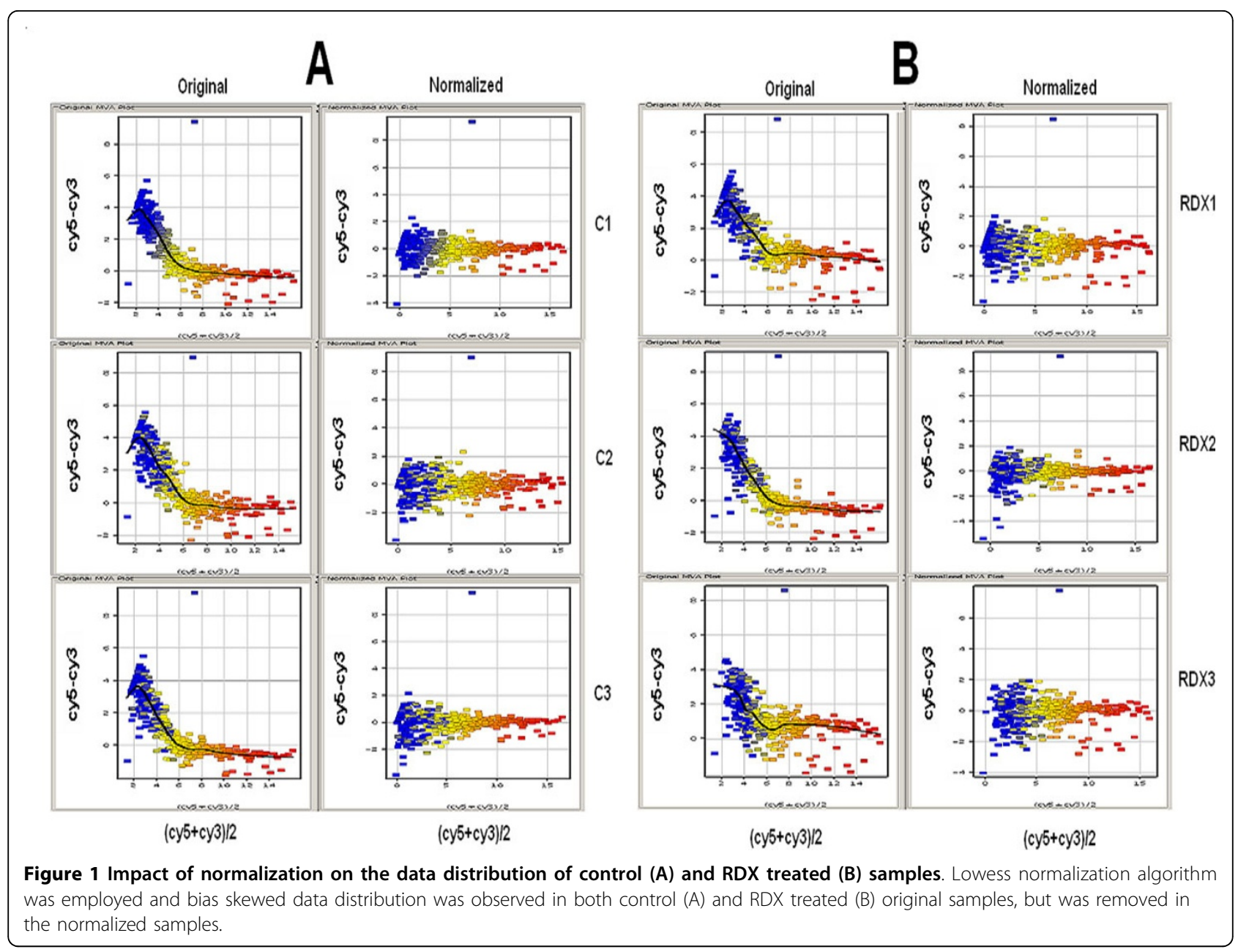

genes that were targeted by two or more of these regulated miRNAs. A total of 1589 target genes were predicted. Based on the IPA tool, we analyzed the physiological development and function categories of these target genes. Top significant enriched development and function terms were presented in Figure 3A. We could observe that the nervous system development and function category in the

Table 1 Significantly regulated miRNAs in rat brain after exposure to RDX.

\begin{tabular}{llll}
\hline MiRNA name & p-value & Fold change & Regulation \\
\hline miR-98 & 0.006792 & 1.715814 & up \\
miR-27b & 0.029563 & 1.59366 & up \\
miR-135a & 0.019873 & 1.542563 & up \\
miR-7a & 0.048486 & 1.349329 & up \\
miR-674-5p & 0.009661 & 1.263634 & up \\
miR-27a & 0.041365 & 1.227918 & up \\
miR-320 & 0.04012 & -1.582334 & down \\
miR-129* & 0.039644 & -1.476831 & down \\
miR-342-3p & 0.026962 & -1.28396 & down \\
\hline
\end{tabular}

top list, which included 256 target genes (Additional file 1) of the miRNAs. Another function category behavior which is also associated with brain function was in the top list, which contained 86 genes.

Figure 3B exhibited top 10 significant canonical pathways enriched in the 1589 target genes. Among them, two canonical pathways axonal guidance signaling and reelin signaling in neurons were clearly involved in nervous system function. Seventy six target genes (Additional file 2) fell into the axonal signaling pathway which is related to neurotransmitters and other nervous System Signaling. Twenty-two genes (Additional file 2) play a role in reelin signaling in neurons pathway.

In order to find out the interaction between target genes, we generated common networks using the IPA software. The target genes of the regulated miRNAs by RDX were uploaded into the IPA software tool. Networks formed by these genes were then mathematically generated according to their connectivity. Figure 4 illustrates the graphical representation of themolecular relationships between genes, which is one of gene networks 


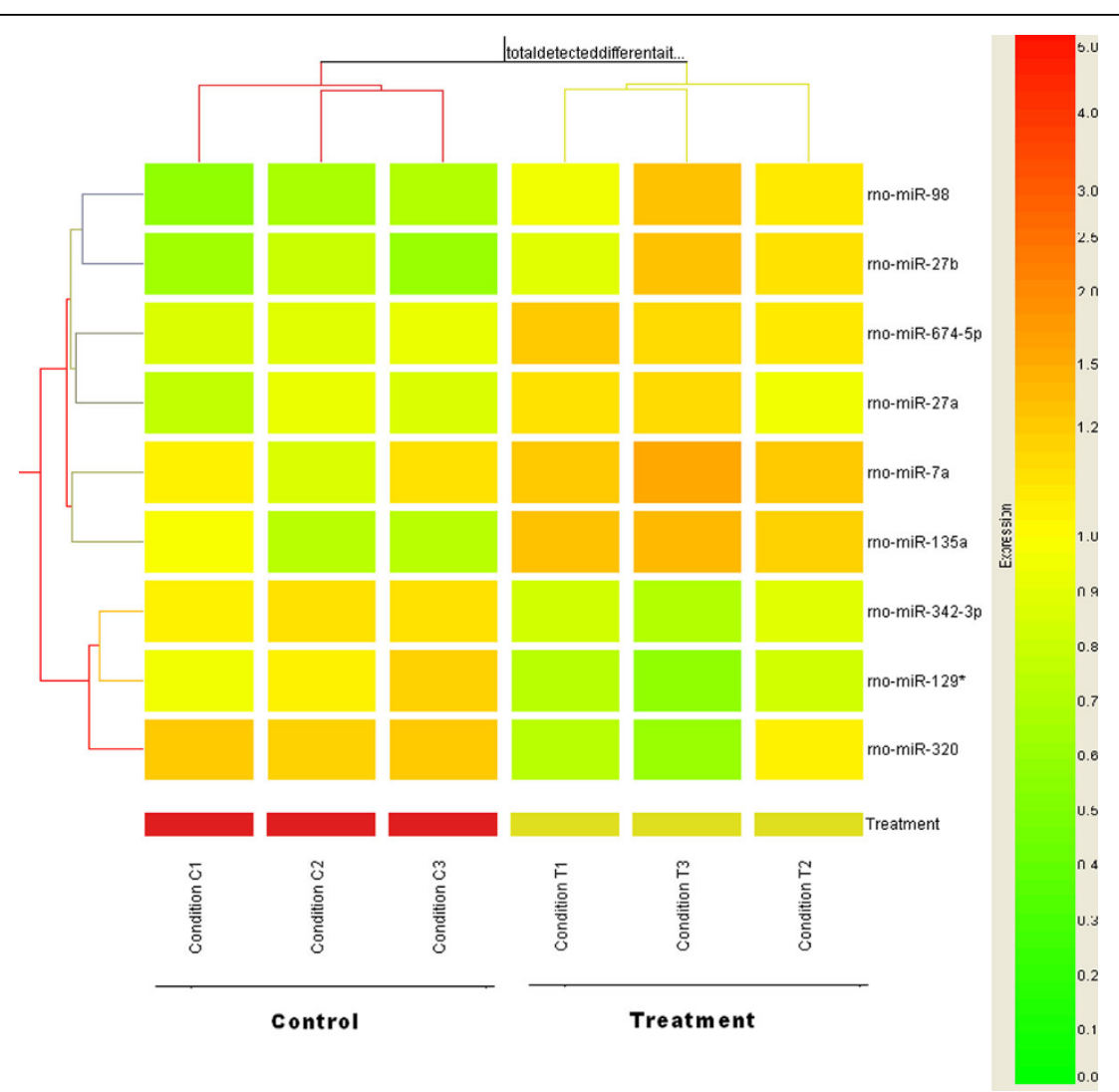

Figure 2 Hierarchical clustering of differentially expressed miRNAs induced by RDX. Nine differentially expressed miRNAs (horizontal axis) were used for a Two-Way hierarchical clustering across all the control and RDX treated samples (vertical axis). A Pearson correlation algorithm was applied to calculate the distances between transcripts or between conditions. The relative level of gene expression is indicated by the color scale at the right side.

developed by IPA with the highest score (39). The network is associated with cellular development, nervous system development and function, organism development. Several transcription factors such as DLX2, SOX2, NKX2-2, PAX6, OTX2, BTG1 and BTG2, and protein kinases such as PTRZ1, MAPK14 were found to be involved in the network especially related to nervous system development and function. This network also exhibited that many of these genes were regulated by each other either directly or indirectly.

\section{A}

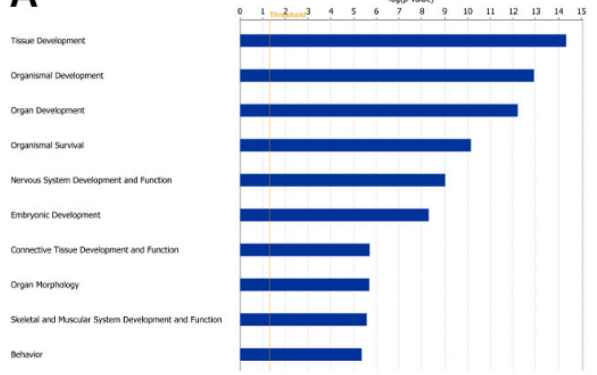

B

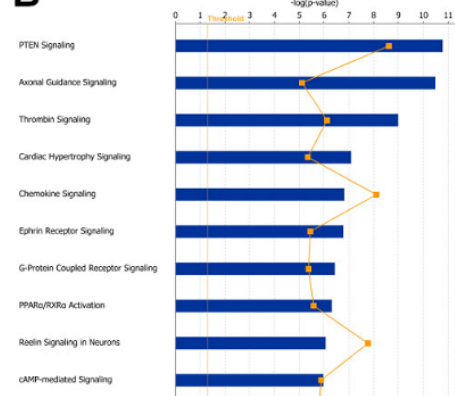

Figure 3 Most significantly physiological processes (A) and canonical pathways (B) of the putative target genes of RDX regulated miRNAs. Top ten physiological processes (A) and pathways (B) were selected to present. The putative target genes of RDX regulated miRNAs in rat brain tissues were used to run the Ingenuity pathway tool. The bigger the -log(p-value) of a pathway is, the more significantly the physiological process or pathway is regulated. The threshold lines represent a $p$ value with 0.05 . 


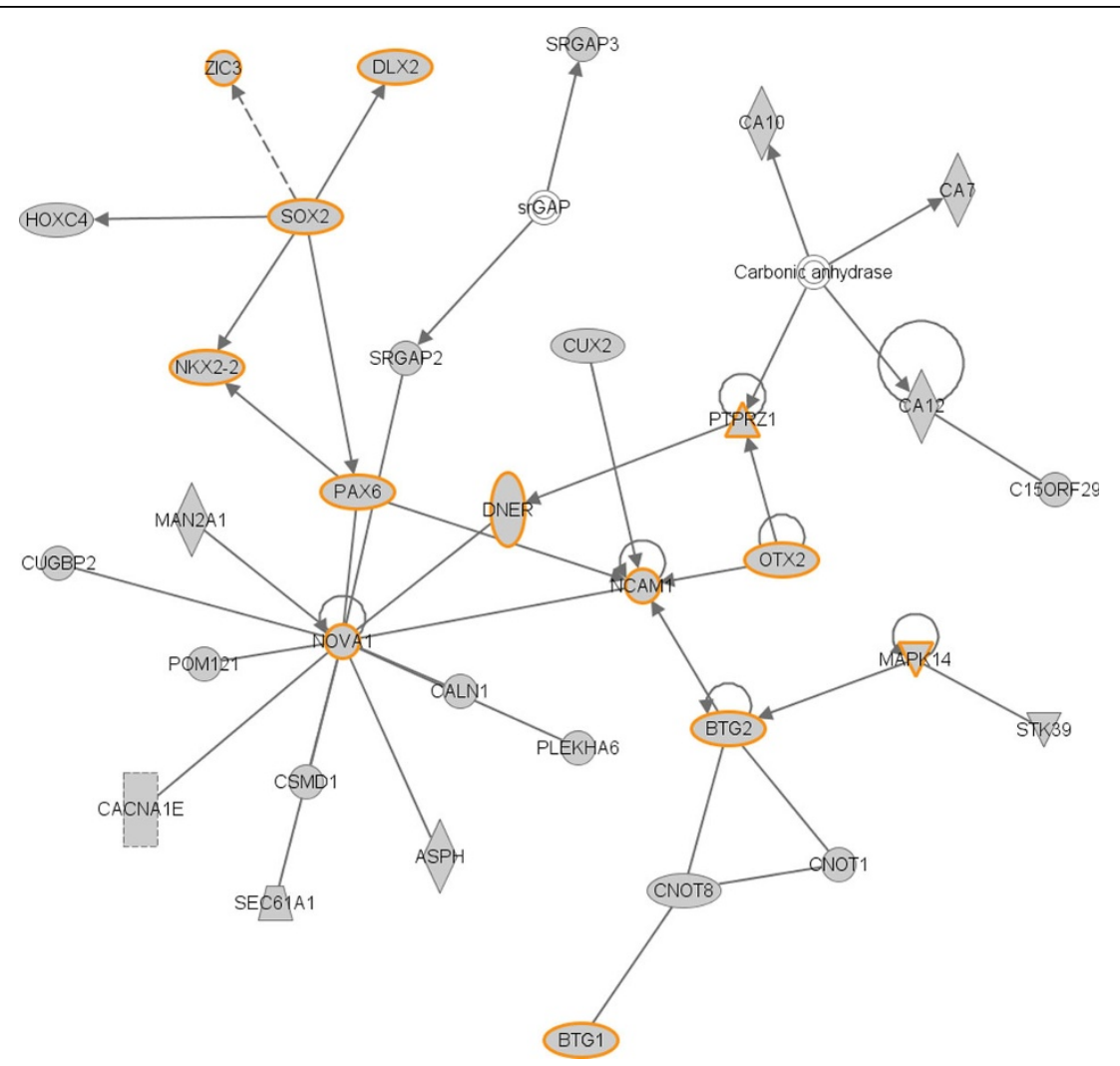

Figure 4 Gene network of the putative target genes of RDX regulated miRNAs. The putative target genes of RDX induced differentially expressed miRNAS were used to run the IPA tool for gene network analysis. The orange highlighted genes are involved in nervous system development function. The networks score described in Materials and Methods for the network is 39. The solid lines connecting molecules here represents a direct relation and dotted lines an indirect relation.

\section{Comparison of miRNA target genes and mRNA expression profile}

The overlap between putative targets of miRNAs and the expression of mRNAs offers the further information on the biological processes and specific miRNA regulated gene networks. To reach the goal, we also conducted mRNA microarray analysis. Rats were treated with or without RDX at $(47 \mathrm{mg} / \mathrm{kg})$ for $48 \mathrm{~h}$, subsequently the mRNA level of different genes in the brain tissues were monitored by cDNA micorarray techniques with approximately 8,000 probes. Using a Bayesian statistical analysis with 5\% FDR, a total of 123 genes were significantly regulated by RDX. Of these genes, 60 genes were up-regulated (Additional file 3) and 63 genes were down-regulated (Additional file 4). In total, 15 (12.2\%) of these regulated genes were putative targets of miRNAs regulated by RDX. Ten and 5 of these overlapped genes were down-regulated and up-regulated by RDX respectively (Table 2 ). This relationship maybe inverse, for instance, down-regulated miRNAs and over-expressed targets and up-regulated miRNAs and down-regulated
Table 2 Overlapped genes between putative target genes of miRNAs and differential mRNA genes regulated by RDX.

\begin{tabular}{lll}
\hline Symbol & Entrez Gene Name & Regulation \\
\hline HMGCR & 3-hydroxy-3-methylglutaryl-CoA reductase & Up \\
LITAF & lipopolysaccharide-induced TNF factor & Up \\
NPTX2 & neuronal pentraxin II & Up \\
SLC38A2 & solute carrier family 38, member 2 & Up \\
VGF & VGF nerve growth factor inducible & Up \\
BANP & BTG3 associated nuclear protein & Down \\
C5ORF13 & chromosome 5 open reading frame 13 & Down \\
CALD1 & caldesmon 1 & Down \\
CEP350 & centrosomal protein 350 kDa & Down \\
FAM82A2 & family with sequence similarity 82, member A2 & Down \\
KIAA1033 & KIAA1033 & Down \\
POLE4 & polymerase (DNA-directed), epsilon 4 (p12 & Down \\
& subunit) & \\
ROCK2 & Rho-associated, coiled-coil containing protein & Down \\
SLC35E4 & kinase 2 & \\
SULF1 & solute carrier family 35, member E4 & Down \\
\hline
\end{tabular}


Table 3 The relationship between miRNAs and their target genes regulated by RDX.

\begin{tabular}{llll}
\hline \multicolumn{2}{c}{ MiRNAs } & \multicolumn{1}{c}{ Target Genes } \\
\hline Names & Regulation & Up & Down \\
\hline miR-135a & Up & KIAA1033, CEP350, \\
& & ROCK2 \\
miR-320 & Down & BANP, CALD1, POLE4 \\
miR-98 & Up & SULF1 \\
miR-129* & Down & BANP, FAM82A2 \\
miR-27ab & Up & HMGCR, LITAF, & CALD1, C5orf13, \\
& & NPTX2 & KIAA1033 \\
miR-342- & Down & VGF & KIAA1033 \\
3P & & & \\
miR-7a & Up & SLC38A2 & POLE4, SLC35E4, \\
miR-674- & Up & VGF & C5orf13 \\
$5 p$ & & & \\
\hline
\end{tabular}

targets. As shown in table 3 the targets of miR-135a, miR98, and most of the targets of miR-7a have an inverse relationship with their responsive miRNAs. However, some positive relationship also occurred here. MiR-320, rno-
miR-129* and their targets were both repressed by RDX. Rno-miR-647-5p and its target gene VGF were both induced by RDX (Table 3).

Biological functional analysis revealed that more than half (8) of the overlapped genes are involved in neurological diseases and nervous system function (Table 4). These genes included HMGCR, BANP, C5ORF13, ROCK2, LITAF, POLE4, SULF1 and VGF.

\section{Comparative pathway and network analysis}

Besides identifying common genes between putative target genes of regulated miRNAs and mRNA expression, we further compared common pathways. Pathway analyses were performed using the IPA tool. Two gene lists: putative target genes of regulated miRNAs and differential genes from the mRNA microarray profiles were uploaded into the IPA tool for pathway mapping. Based on all mapped pathways, 52 pathways were shared by these two gene lists (Figure $5 \mathrm{~A}$ ), which is $61.9 \%$ of the 84 mapped pathways of the mRNA genes regulated by RDX. Using only significantly mapped pathways ( $\mathrm{p}$ value $<=0.05$ ), 5 pathways were overlapped (Figure $5 \mathrm{~B}$ ), which is $55.6 \%$ of

Table 4 Over half (8) of the overlapped target genes are involved in neurological disease and nervous system function.

\begin{tabular}{|c|c|c|c|c|}
\hline Category & Function Annotation & P-value & Molecules & $\begin{array}{l}\# \\
\text { Molecules }\end{array}$ \\
\hline Neurological Disease & granular cell tumor & $\begin{array}{l}1.98 \mathrm{E}- \\
03\end{array}$ & HMGCR & 1 \\
\hline Neurological Disease & Huntington's disease & $\begin{array}{l}2.04 \mathrm{E}- \\
03\end{array}$ & BANP, C5ORF13, HMGCR, ROCK2 & 4 \\
\hline Neurological Disease & subarachnoid hemorrhage & $\begin{array}{l}2.98 \mathrm{E}- \\
03\end{array}$ & HMGCR & 1 \\
\hline Neurological Disease & neurofibromatosis & $\begin{array}{l}6.93 \mathrm{E}- \\
03\end{array}$ & HMGCR & 1 \\
\hline Neurological Disease & neurological disorder & $\begin{array}{l}1.11 \mathrm{E}- \\
02\end{array}$ & $\begin{array}{l}\text { BANP, C5ORF13, HMGCR, LITAF, POLE4, } \\
\text { ROCK2 }\end{array}$ & 6 \\
\hline Neurological Disease & meningitis & $\begin{array}{l}1.68 \mathrm{E}- \\
02\end{array}$ & POLE4 & 1 \\
\hline Neurological Disease & Charcot-Marie-Tooth disease & $\begin{array}{l}2.16 \mathrm{E}- \\
02\end{array}$ & LITAF & 1 \\
\hline Neurological Disease & medulloblastoma & $\begin{array}{l}3.90 \mathrm{E}- \\
02\end{array}$ & POLE4 & 1 \\
\hline Neurological Disease & $\begin{array}{l}\text { migration of brain cancer cell } \\
\text { lines }\end{array}$ & $\begin{array}{l}4.09 E- \\
02\end{array}$ & C5ORF13 & 1 \\
\hline Neurological Disease & stroke & $\begin{array}{l}4.19 \mathrm{E}- \\
02\end{array}$ & HMGCR & 1 \\
\hline Neurological Disease & neuropathy & $\begin{array}{l}4.77 \mathrm{E}- \\
02\end{array}$ & HMGCR, LITAF & 2 \\
\hline $\begin{array}{l}\text { Nervous System Development and } \\
\text { Function }\end{array}$ & morphology of dendritic spines & $\begin{array}{l}9.89 \mathrm{E}- \\
03\end{array}$ & ROCK2 & 1 \\
\hline $\begin{array}{l}\text { Nervous System Development and } \\
\text { Function }\end{array}$ & sprouting of neurites & $\begin{array}{l}2.07 \mathrm{E}- \\
02\end{array}$ & SULF1 & 1 \\
\hline $\begin{array}{l}\text { Nervous System Development and } \\
\text { Function }\end{array}$ & differentiation of neurons & $\begin{array}{l}2.42 \mathrm{E}- \\
02\end{array}$ & C5ORF13, VGF & 2 \\
\hline $\begin{array}{l}\text { Nervous System Development and } \\
\text { Function }\end{array}$ & retraction of neurites & $\begin{array}{l}4.57 \mathrm{E}- \\
02\end{array}$ & ROCK2 & 1 \\
\hline
\end{tabular}




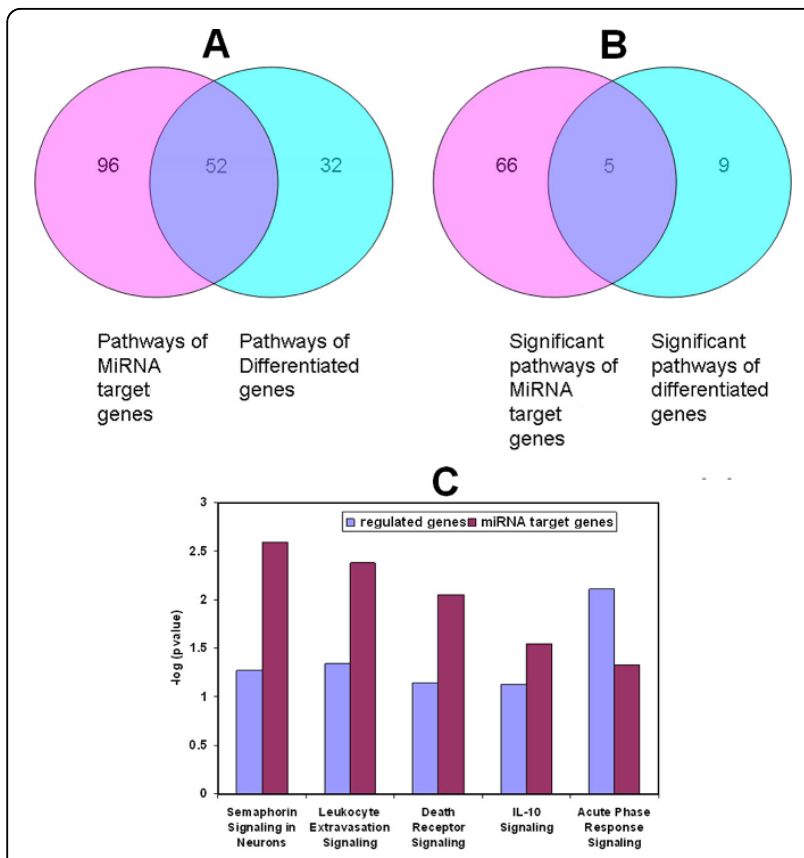

Figure 5 Comparison of canonical pathways based on the putative target genes of RDX regulated miRNAs and differentiated mRNA genes. Overlapped all mapped pathways (A) or significant pathways (B) based on the putative target genes of RDX regulated miRNAs and differentiated mRNA genes, are presented in the Venn diagrams. The IPA tool was used for the pathway analyses. A pathway enrichment $p$ value less than 0.05 was considered as significant. The overlapped significant pathway names and their significance are depicted too (C).

the 14 significant pathways of the mRNA genes affected by RDX. The five common significant pathways are shown in Figure 5C. Clearly we could observe one significant pathway seaphorin signaling in neurons is involved in neural system function.

Interestingly, a large group of genes regulated by RDX through the mRNA profiles were immune and inflammatory response genes. For example, the most significantly regulated pathway for the regulated mRNA gene list (Figure 5C) was acute phase response signaling. But most of these immune and inflammatory response genes were not significantly represented in the putative target genes of miRNAs regulated by RDX. MiRNAs may indirectly regulate these mRNA genes through directly regulating other genes. Using both immune and inflammatory response genes from both putative target genes of regulated miRNAs and regulated mRNA genes, a gene network was constructed (Figure 6). We could obviously see the gene interaction between these two sources of genes. For example, the putative target gene IL10 could regulate mRNA genes TIMP1, GZMB and TNF. TNF could also regulate putative target genes MNT and DUSP5 to carry out immune and inflammatory functions.

\section{Verification of miRNA microarray responses using real time QRT-PCR}

To verify miRNA microarray results, we selected $4 \mathrm{miR}$ NAs to perform real time quantitative PCR (QRT-PCR) for the RDX exposed brain samples and their controls. As illustrated in Figure 7, miR-27b and miR-7a were up-regulated whereas miR-343-3p and miR-320 were down-regulated by RDX. The QRT-PCR results were consistent with the miRNA microarray results (Table 1 ).

\section{Discussion}

\section{MiRNA alteration in response to RDX exposure}

This is the first report that comprehensively analyzes the rat brain miRNA expression profile in response to RDX exposure. We found that 9 miRNAs whose expression was altered in rat brain tissues by RDX. Among them, 6 miRNAs were up-regulated and 3 miRNAs were down-regulated. Two miRNAs miR-98 and miR-7a were induced in rat brain tissues after exposure to RDX, and they were also up-regulated in mouse brain tissues treated with RDX [11]. MiR-27b and miR-320 were upregulated and down-regulated respectively in our study, but not significantly changed in mouse brain tissue. However they were altered in mouse liver tissues with the same direction as rat brain tissues by RDX. Some of our regulated miRNA are not shown in Zhang's regulated miRNA lists, and also RDX induced much more miRNAs in mouse brain than our case. This should not be hard to explain, because Zhang's study is a long term exposure (28 days), we only used 2 day short exposure. It may also have dose and species specific responses.

Some of these 9 regulated miRNAs have been shown to participate in neurological diseases and neural system function. For instance, miR-7a was reported to be involved in glioblastoma [26] and Parkinson's disease [27]. MiR-27a and MiR-129 were shown to play a role in autism spectrum disorder (ASD) [28]. MiR-320 was observed to be involved in neurodegenration [12] and retinoblastoma [29]. MiR-342-3p has been found to play a role in neurodegenration [12] and prion disease [30]. Our results indicate that RDX could induce neurological diseases and neurotoxicity through regulating these miRNAs.

\section{The putative targets of RDX regulated miRNAs involved in neurotoxicity}

Existing studies have exhibited that RDX exposure induced adverse central nervous system (CNS) syndromes such as convulsion, epileptic seizure, and loss of reflexes in human and experimental animals [1,5-7]. However, how RDX causes neurotoxicity at molecular level is not well known. Through the functional analyses of these target genes, we found that multiple evidences to support that RDX affects neural system development and neurological pathways. Nervous system development and 


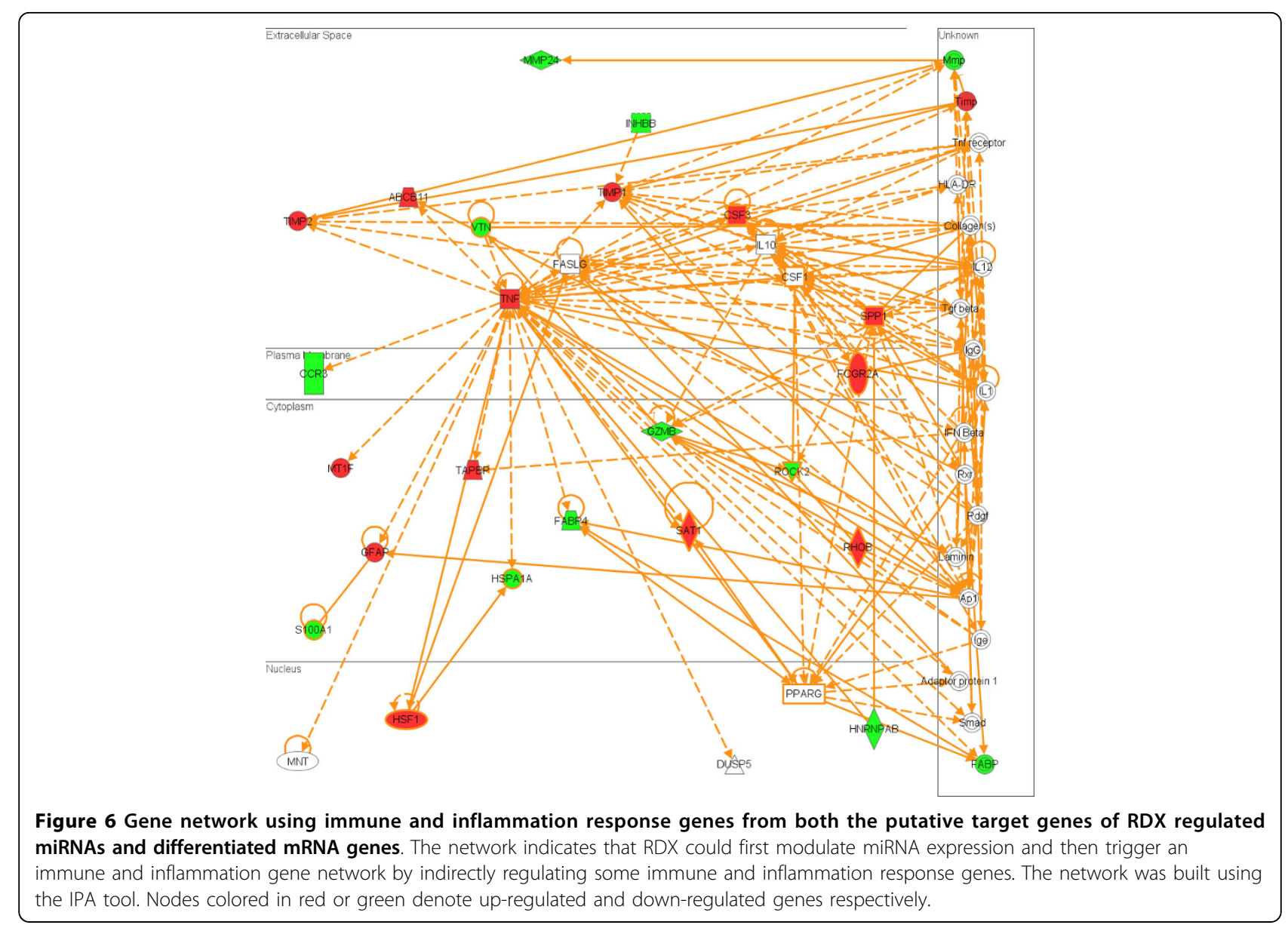

function is in the top significant physiological system development and function category (Figure 3A). Axonal guidance signaling pathway is in the top 2 significantly pathways enriched in the canonical pathway analysis

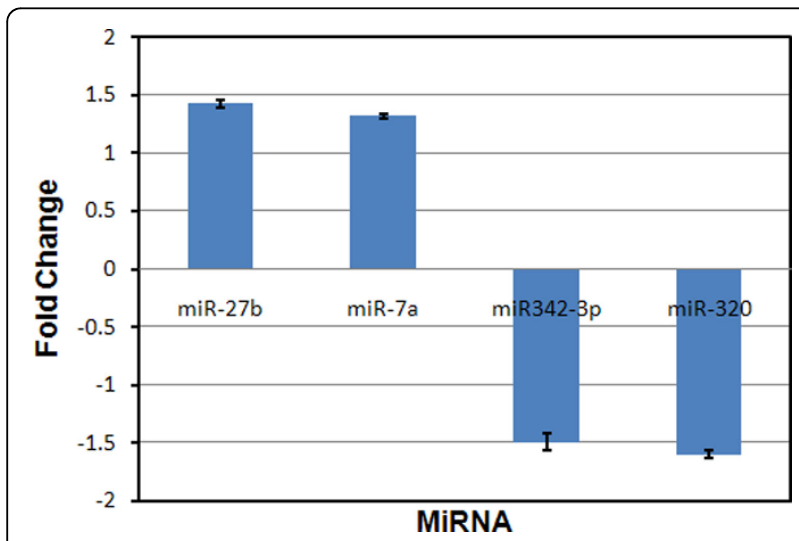

Figure 7 Verification of miRNA microarray responses using real time QRT-PCR. The fold changes represent the expression values of the miRNAs of the RDX-treated versus control samples. Values refer to the mean \pm SD of three independent samples, each run in triplicate.
(Figure 3B). The pathway plays a crucial role in neuronal connections that are formed by the extension of axons, which migrate to reach their synaptic targets. The axonal growth cone, located at the axon leading edge, contains receptors that sense attractive and repulsive guidance cues, which help navigate the axon to its final destination [31-35].

Another important pathway in the top significant pathway list (Figure 3B) is reelin signaling in neurons. Reelin is a large extracellular glycoprotein involved in the development of architectonic patterns, and Cajal-Retzius cells of the human embryonic marginal zone are the primary site of synthesis for reelin. In the hippocampus, reelin also regulates the growth and/or distribution of afferent entorhinal and commissural axons. The genes in the pathway provide molecular mechanisms that control brain development and, potentially, the pathogenesis of neurodegenerative disorders [36-38]. Moreover, the most significant gene network based on the putative target genes is involved in neural system function and development (Figure 4). Regulating the gene network and the pathways could partially explain the molecular mechanism for RDX induced neurotoxicity. 
Overlapped genes between putative targets of regulated miRNAs and differential mRNA genes revealing new markers for RDX induced neurotoxicity

We found 15 overlapped genes, which are about $12 \%$ of differential mRNA genes (123 genes). The number is not big and the percentage is similar to other studies. For instance, the overlapped target genes was $12 \%$ in prion induced miRNA and mRNA profiles [12]. The Several reasons could account for the small portion of overlapping. First, the rat mRNA array is not the whole genome array, only about one third of the genome (8000 probes) is used, but the prediction of miRNA targets is based on the whole genome. Second, the prediction is static, which means the targets are predicted based on any condition, but the mRNA genes are differentially expressed at a certain condition. Third, the predictive putative targets may contain many false positives. Fourth, technical limitation for both miRNA and mRNA arrays may also leave out potential overlapped genes.

We did see an inverse relationship between the regulated miRNA expression and their target mRNA genes (Table 3). However, we also observed a positive relationship between the expression of the miRNA and their target genes (Table 3). Normally the enhancement of miRNA expression inhibits target mRNA expression, but it could also facilitate target mRNA expression $[16,17]$. Over half of the overlapped target genes are involved in neurological disease and nervous system function (Table 4). If we only consider the inverse correlation between miRNAs and their target genes, particularly those target genes involved in neurological function that are repressed due to the over-expression of the regulated miRNAs, several target genes stand out and are SULF1, C5ORF13, ROCK2, POLE4. SULF1 is necessary for sprouting of neurite, and is involved in neurological disorder, ischemic stroke and bipolar disorder [39]. C5ORF13 plays a role in accelerating nerve regeneration of the axtomized facial nerve and has been found to involve in multiple neurological diseases [40]. ROCK2, a Rho-associated, coiled-coil containing protein kinase, is involved in reaction of neurites [41]. POLE4 also contributes to multiple neurological diseases (Table 4 ). Here we also want to point out one target gene HMGCR whose expression is increased by RDX. It has been found to its over expression could induce stroke and seizure $[42,43]$. The up-regulation of HMGCR could be one reason for RDX induced stroke and seizure. But we only found up-regulated miRNAs miR-27a and miR-27b that could target HMGCR. There may be unknown miRNAs that target HMGCR and are down-regulated by RDX. Therefore, based on both miRNA and mRNA profiles, we come out a hypothetic model that could partially explain RDX trigged neurological disorder and neurotoxicity. RDX could first induce the expression of miR-71, miR-27ab, miR-98, and $\mathrm{miR}-135 \mathrm{a}$, then reduce the expression of POLE4, C5ORF13, SULF1 and ROCK2, and finally induce neurotoxicity. RDX induced miR-27ab overexpression, or reduce the expression of unknown miRNAs, could consequently up-regulate HMGCR expression to cause neurotoxicity too (Figure 8 ). The miRNAs and genes in the model could be new biomarkers for RDX induced neurotoxicity, which could work together with RDX binding to GABAa receptor to explain RDX caused brain damage.

\section{MiRNAs mediated gene network of immune and inflammation response genes regulated by RDX} Immune and inflammation response genes are highly enriched in differentially expressed mRNAs after exposure to RDX, but not in the putative target genes of regulated miRNAs. Interestingly, the immune and inflammation response genes connected network (Figure 6) indicates that RDX could first modulate miRNA expression and then trigger an immune and inflammation gene network. For instance, miR-98 could target IL10, which then up-regulate TNF, which induces the expression of the transcription factor HSF1 (Figure 6), to carry out immune functions. RDX regulated immune response could contribute to RDX induced neurotoxicity and other toxicities as well as animal defending reaction response to RDX exposure.

\section{Conclusions}

Our results demonstrate that integrating miRNA and mRNA profiles is valuable to indentify novel biomarkers and molecular mechanisms for RDX-induced neurological disorder and neurotoxicity. RDX could first induce the expression of miR-71, miR-27ab, miR-98, and miR-135a,

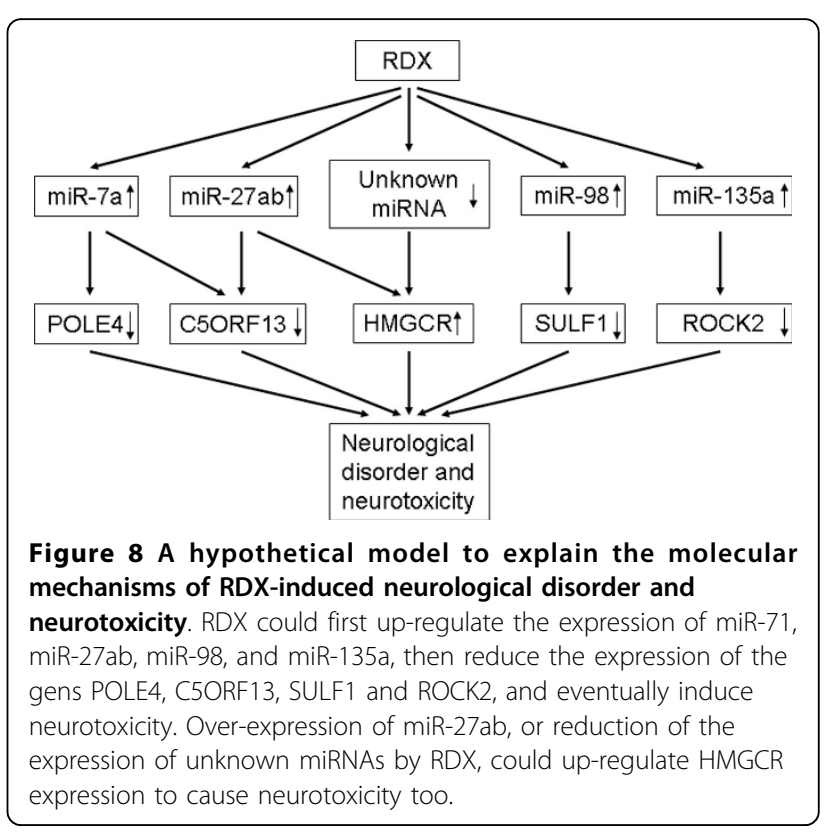


then reduce the expression of POLE4, C5ORF13, SULF1 and ROCK2, and finally induce neurotoxicity, which provides an alternative mechanism to explain RDX induced neurotoxicity.

\section{Additional material}

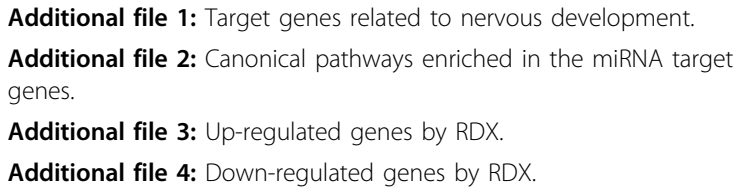

\section{Competing interests}

The authors declare that they have no competing interests.

\section{Authors' contributions}

YD and EJP designed and coordinated the study. YD, JA, MQY, YB, DZ, CL and ZW analyzed miRNA and mRNA array data. XG, MSW, BLE and SAM performed the experiments. YD drafted the manuscript. YD and EJP revised and finalized the manuscript which was read and approved by all authors.

\section{Acknowledgements}

This work and its publication were supported by research grants from Natural Science Foundation Hubei Province of China (2011CDB236) and United States National Institutes of Health (NIH). MQY was supported by NIH/NIGMS 5P20GM10342913 and ASTA award \# 15-B-23. YD was supported by $\mathrm{NIH} / \mathrm{NCl}$ R21CA164764.

This article has been published as part of BMC Genomics Volume 15 Supplement 11, 2014: Selected articles from the 2014 International Conference on Advances in Big Data Analytics. The full contents of the supplement are available online at http://www.biomedcentral.com/ bmcgenomics/supplements/15/S11.

\section{Authors' details}

${ }^{1}$ Wuhan University of Science and Technology, Wuhan, Hubei 430081, China. ${ }^{2}$ Departments of Internal Medicine and Biochemistry, Rush University Medical Center, Chicago, IL 60612, USA. ${ }^{3}$ Bristol Bay Native Corporation, Vicksburg, Mississippi 39180, USA. ${ }^{4}$ Department of Biology, Hong Kong Baptist University, Kowloon, Hong Kong SAR, China Stem Cell \& Regenerative Medicine Consortium, LKS Faculty of Medicine and Department of Physiology, The University of Hong Kong, Hong Kong SAR, China. ${ }^{5}$ Center for Systems Biology, School of Mathematical Sciences, Soochow University, Suzhou, Jiangsu 215006, China. ' United States Army Engineer Research and Development Center, 3909 Halls Ferry Road, Vicksburg, Mississippi 39180, USA. ${ }^{7}$ School of Pharmacy, University of Louisiana at Monroe, Monroe, Louisiana, 71209, USA. ${ }^{8}$ School of Computer Science and Technology, Wuhan University of Science and Technology, Wuhan, Hubei, PR China. ${ }^{9}$ MidSouth Bioinformatics Center, Department of Information Science, George W. Donaghey College of Engineering and Information Technology, University of Arkansas at Little Rock, 2801 S. University Avenue, Little Rock, Arkansas, 72204, USA. ${ }^{10}$ Joint Bioinformatics Graduate Program, University of Arkansas at Little Rock and University of Arkansas for Medical Sciences, Little Rock, Arkansas 72204, USA.

Published: 16 December 2014

\section{References}

1. Goldberg DJ, Green ST, Nathwani D, McMenamin J, Hamlet N, Kennedy DH: RDX intoxication causing seizures and a widespread petechial rash mimicking meningococcaemia. J R Soc Med 1992, 85:181.

2. Johnson MS, Quinn MJ, Bazar MA, Gust KA, Escalon BL, Perkins EJ: Subacute toxicity of oral 2,6-dinitrotoluene and 1,3,5-trinitro-1,3,5-triazine (RDX) exposure to the northern bobwhite (Colinus virginianus). Environ Toxicol Chem 2007, 26:1481-1487.
3. Quinn MJ, Bazar MA, McFarland CA, Perkins EJ, Gust KA, Johnson MS: Sublethal effects of subacute exposure to RDX (1,3,5-trinitro-1,3,5triazine) in the northern bobwhite (Colinus virginianus). Environ Toxicol Chem 2009, 28:1266-1270.

4. Talmage SS, Opresko DM, Maxwell CJ, Welsh CJ, Cretella FM, Reno PH, Daniel FB: Nitroaromatic munition compounds: environmental effects and screening values. Rev Environ Contam Toxicol 1999, 161:1-156.

5. Burdette L, Cook LL, Dyer RS: Convulsant properties of cyclotrimethylenetrinitramine (RDX): spontaneous audiogenic, and amygdaloid kindled seizure activity. Toxicol Appl Pharmacol 1988, 92:436-444.

6. Pan X, San Francisco MJ, Lee C, Ochoa KM, Xu X, Liu J, Zhang B, Cox SB, Cobb GP: Examination of the mutagenicity of RDX and its $\mathrm{N}$-nitroso metabolites using the Salmonella reverse mutation assay. Mutat Res 2007, 629:64-69.

7. Testud F, Glanclaude JM, Descotes J: Acute hexogen poisoning after occupational exposure. J Toxicol Clin Toxicol 1996, 34:109-111.

8. Williams LR, Aroniadou-Anderjaska V, Qashu F, Finne H, Pidoplichko V, Bannon DI, Braga MF: RDX binds to the GABA(A) receptor-convulsant site and blocks $G A B A(A)$ receptor-mediated currents in the amygdala: a mechanism for RDX-induced seizures. Environ Health Perspect 2011, 119:357-363.

9. Williams LR, Wong K, Stewart A, Suciu C, Gaikwad S, Wu N, Dileo J, Grossman L, Cachat J, Hart P, et al: Behavioral and physiological effects of RDX on adult zebrafish. Comp Biochem Physiol C Toxicol Pharmacol 2012, 155:33-38.

10. Garcia-Reyero N, Habib T, Pirooznia M, Gust KA, Gong P, Warner C, Wilbanks M, Perkins E: Conserved toxic responses across divergent phylogenetic lineages: a meta-analysis of the neurotoxic effects of RDX among multiple species using toxicogenomics. Ecotoxicology 2011, 20:580-594.

11. Zhang $B$, Pan $X:$ RDX induces aberrant expression of microRNAs in mouse brain and liver. Environ Health Perspect 2009, 117:231-240.

12. Saba R, Goodman CD, Huzarewich RL, Robertson C, Booth SA: A miRNA signature of prion induced neurodegeneration. PLOS One 2008, 3:e3652.

13. Lewis BP, Burge CB, Bartel DP: Conserved seed pairing, often flanked by adenosines, indicates that thousands of human genes are microRNA targets. Cell 2005, 120:15-20.

14. Karres JS, Hilgers V, Carrera I, Treisman J, Cohen SM: The conserved microRNA miR-8 tunes atrophin levels to prevent neurodegeneration in Drosophila. Cell 2007, 131:136-145.

15. Xiao C, Calado DP, Galler G, Thai TH, Patterson HC, Wang J, Rajewsky N, Bender TP, Rajewsky K: MiR-150 controls B cell differentiation by targeting the transcription factor c-Myb. Cell 2007, 131:146-159.

16. Leung AK, Sharp PA: microRNAs: a safeguard against turmoil? Cell 2007, 130:581-585.

17. Vasudevan S, Tong $Y$, Steitz JA: Switching from repression to activation: microRNAs can up-regulate translation. Science 2007, 318:1931-1934.

18. National Research Council: Guide for the care and use of laboratory animals National Academy Press, Washington D.C; 1996.

19. Perkins EJ, Bao W, Guan X, Ang CY, Wolfinger RD, Chu TM, Meyer SA, Inouye LS: Comparison of transcriptional responses in liver tissue and primary hepatocyte cell cultures after exposure to hexahydro-1, 3, 5trinitro-1, 3, 5-triazine. BMC Bioinformatics 2006, 7(Suppl 4):S22.

20. Deng Y, Meyer SA, Guan X, Escalon BL, Ai J, Wilbanks MS, Welti R, GarciaReyero N, Perkins EJ: Analysis of common and specific mechanisms of liver function affected by nitrotoluene compounds. PLoS One 2011, 6: e14662.

21. Deng $Y$, Johnson DR, Guan $X$, Ang CY, Ai J, Perkins EJ: In vitro gene regulatory networks predict in vivo function of liver. BMC Syst Biol 2010, 4:153.

22. Griffiths-Jones S, Grocock RJ, van Dongen S, Bateman A, Enright AJ: miRBase: microRNA sequences, targets and gene nomenclature. Nucleic Acids Res 2006, 34:D140-D144.

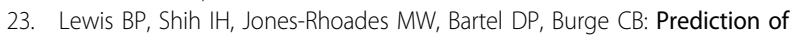
mammalian microRNA targets. Cell 2003, 115:787-798.

24. Krek A, Grun D, Poy MN, Wolf R, Rosenberg L, Epstein EJ, Macmenamin P, da P, Gunsalus KC, Stoffel M, et al: Combinatorial microRNA target predictions. Nat Genet 2005, 37:495-500

25. Bredel M, Bredel C, Juric D, Harsh GR, Vogel H, Recht LD, Sikic Bl: Functional network analysis reveals extended gliomagenesis pathway 
maps and three novel MYC-interacting genes in human gliomas. Cancer Res 2005, 65:8679-8689.

26. Kefas B, Godlewski J, Comeau L, Li Y, Abounader R, Hawkinson M, Lee J, Fine $H$, Chiocca EA, Lawler $S$, et al: microRNA-7 inhibits the epidermal growth factor receptor and the Akt pathway and is down-regulated in glioblastoma. Cancer Res 2008, 68:3566-3572.

27. Junn E, Lee KW, Jeong BS, Chan TW, Im JY, Mouradian MM: Repression of alpha-synuclein expression and toxicity by microRNA-7. Proc Natl Acad Sci USA 2009, 106:13052-13057.

28. Abu-Elneel K, Liu T, Gazzaniga FS, Nishimura Y, Wall DP, Geschwind DH, Lao K, Kosik KS: Heterogeneous dysregulation of microRNAs across the autism spectrum. Neurogenetics 2008, 9:153-161.

29. Zhao Y, Lu S, Wu L, Chai G, Wang H, Chen Y, Sun J, Yu Y, Zhou W, Zheng Q, et al: Acetylation of p53 at lysine $373 / 382$ by the histone deacetylase inhibitor depsipeptide induces expression of p21(Waf1/ Cip1). Mol Cell Biol 2006, 26:2782-2790.

30. Montag J, Hitt R, Opitz L, Schulz-Schaeffer WJ, Hunsmann G, Motzkus D: Upregulation of miRNA hsa-miR-342-3p in experimental and idiopathic prion disease. Mol Neurodegener 2009, 4:36.

31. Govek EE, Newey SE, Van Aelst L: The role of the Rho GTPases in neuronal development. Genes Dev 2005, 19:1-49.

32. Uchida Y, Ohshima T, Sasaki Y, Suzuki H, Yanai S, Yamashita N, Nakamura F, Takei $\mathrm{K}$, Ihara Y, Mikoshiba $\mathrm{K}$, et al: Semaphorin3A signalling is mediated via sequential Cdk5 and GSK3beta phosphorylation of CRMP2: implication of common phosphorylating mechanism underlying axon guidance and Alzheimer's disease. Genes Cells 2005, 10:165-179.

33. Garbe DS, Bashaw GJ: Axon guidance at the midline: from mutants to mechanisms. Crit Rev Biochem Mol Biol 2004, 39:319-341.

34. Gianakopoulos PJ, Skerjanc IS: Hedgehog signaling induces cardiomyogenesis in P19 cells. J Biol Chem 2005, 280:21022-21028.

35. Charron F, Tessier-Lavigne M: Novel brain wiring functions for classical morphogens: a role as graded positional cues in axon guidance. Development 2005, 132:2251-2262.

36. Chen Y, Beffert U, Ertunc M, Tang TS, Kavalali ET, Bezprozvanny I, Herz J: Reelin modulates NMDA receptor activity in cortical neurons. J Neurosci 2005, 25:8209-8216.

37. Yip YP, Kronstadt-O'Brien P, Capriotti C, Cooper JA, Yip JW: Migration of sympathetic preganglionic neurons in the spinal cord is regulated by Reelin-dependent Dab1 tyrosine phosphorylation and CrkL. J Comp Neurol 2007, 502:635-643.

38. Akopians AL, Babayan AH, Beffert U, Herz J, Basbaum Al, Phelps PE: Contribution of the Reelin signaling pathways to nociceptive processing. Eur J Neurosci 2008, 27:523-537.

39. Ai X, Kitazawa T, Do AT, Kusche-Gullberg M, Labosky PA, Emerson CP Jr: SULF1 and SULF2 regulate heparan sulfate-mediated GDNF signaling for esophageal innervation. Development 2007, 134:3327-3338.

40. Fujitani M, Yamagishi S, Che YH, Hata K, Kubo T, Ino H, Tohyama M, Yamashita T: P311 accelerates nerve regeneration of the axotomized facial nerve. J Neurochem 2004, 91:737-744.

41. Katoh H, Aoki J, Ichikawa A, Negishi M: p160 RhoA-binding kinase ROKalpha induces neurite retraction. J Biol Chem 1998, 273:2489-2492.

42. Kilic E, Kilic U, Matter CM, Luscher TF, Bassetti CL, Hermann DM: Aggravation of focal cerebral ischemia by tissue plasminogen activator is reversed by 3-hydroxy-3-methylglutaryl coenzyme A reductase inhibitor but does not depend on endothelial NO synthase. Stroke 2005, 36:332-336.

43. Freitas RN, Khaw KT, Wu K, Bowman R, Jeffery H, Luben R, Wareham NJ, Rodwell S: HMGCR gene polymorphism is associated with stroke risk in the EPIC-Norfolk study. Eur J Cardiovasc Prev Rehabil 2010, 17:89-93.

doi:10.1186/1471-2164-15-S11-S1

Cite this article as: Deng et al: MicroRNA and messenger RNA profiling reveals new biomarkers and mechanisms for RDX induced neurotoxicity. BMC Genomics 2014 15(Suppl 11):S1.

\section{Submit your next manuscript to BioMed Central and take full advantage of:}

- Convenient online submission

- Thorough peer review

- No space constraints or color figure charges

- Immediate publication on acceptance

- Inclusion in PubMed, CAS, Scopus and Google Scholar

- Research which is freely available for redistribution

Submit your manuscript at www.biomedcentral.com/submit
Biomed Central 